\title{
Small Rewards Leverage Big Change: The Effect of M-Payment Rewards on Charitable Donations
}

\author{
Haijiao Shi \\ Tsinghua University \\ Rong Chen \\ Tsinghua University
}

This study investigates how consumers perceive m-payment rewards and their disposition toward those rewards. Based on theories of mental accounting and across four studies, we find that consumers are more willing to donate when m-payment rewards are random (vs. regular), single (vs. cumulative) or immediate (vs. delayed), because consumers tend to perceive the rewards as more (vs. less) irrelevant to the previous purchase and thus are more (vs. less) willing to donate. We also reinforce the explanation of "rewards as windfall gains" by testing other subsequent choices in lotteries, hedonic consumption and indulgent consumption.

Keywords: Mobile Payment Rewards, Windfall, Donation, Framing Effect

\section{INTRODUCTION}

Angela is paying for the products she purchases from an online vender through Alipay. The total amount is \$9.90. Just after the payment, she observes a small reward (\$0.10) appearing on her payment page. She clicks "Collect." Then, the page automatically pops up with a donation appeal: A penny donation for 10 rural children to drink clean water.

Mobile payment (m-payment) has expanded globally in recent years with the rapid momentum of an avalanche (Shah et al., 2015). Seventy-nine percent of U.S. smartphone users are also mobile shoppers (De Kerviler et al., 2016). The revenue of global m-payment is anticipated to reach over one trillion dollars in 2019 (Mobile Payment volume 2010-2017, 2015). M-payment drastically changes the methods by which consumers purchase products or services (Slade et al., 2015). With the features that are fast, secure and convenient to use in transactions (Mallat, 2007; Slade et al., 2015), m-payment is completely distinguishable from cash and credit card payments. We can pay an accurate amount despite the value of the rightmost digit (e.g., \$5.99 or \$5.92) through m-payment and thus eliminate the process of giving change. However, many payment channels always deliberately provide small rewards to promote repeat usage by consumers. To some extent, these m-payment rewards are equivalent to small cash change. They are all nonrounded or sharp numbers (e.g., $\$ 0.18$ or $\$ 0.12$ ). 
Traditionally, receiving small change from daily purchases has prevailed. Nonrounded numbers (e.g., 2.99) are more frequently used in our daily life than rounded numbers are (e.g., 3.00) (Janiszewski and Uy, 2008; Schindler and Yalch, 2006; Thomas et al., 2010). Since the prices ending in nine or odd prices are just below the rounded price a penny, they increase sales (e.g., Bhattacharya et al., 2012) and appear to be smaller than the rounded price (Thomas and Morwitz, 2005). However, consumers perceive the nonrounded price as inconvenience because it requires more effort and time during transactions (Wieseke et al., 2016). The difference between the cash change and m-payment rewards is that the former is supposed to belong to consumers, whereas the latter is windfall income. Similarly, we also find that rebates can offer consumers discounts or cash refunds (Gilpatric, 2009). In fact, rebates are not guaranteed discounts for consumers ( $\mathrm{Lu}$ and Moorthy, 2007) because they are contingent on certain redemption requirements (Gourville and Soman, 2011). By contrast, small m-payment rewards are provided without any preconditions. We believe that the small m-payment rewards are unexpected, uncertain and irrelevant to the previous purchase as windfall gains. Little empirical research has investigated how consumers deal with these trivial gains.

According to mental accounting theory, consumers code gains and losses into different categories that influence subsequent consumption choices or preferences (Thaler, 1985). Previous studies divide mental accounts into regular income accounts and windfall gain accounts (Kivetz, 1999). Regular income requires more effort and hard work, and as a result, it is less likely to be spent. However, consumers are inclined to classify windfall gains into a temporary and unexpected account that is more likely to be spent mostly on hedonic consumption (e.g., Shafir and Thaler, 2006; Thaler, 1985; Thaler and Shefrin, 1981), interpersonal relationships, entertainment or leisure, and charitable giving (Sussman et al., 2015). The present research proposes that the extent to which consumers perceive the payment rewards bound to the purchase itself influences their disposition toward those rewards, including donations, lotteries, hedonic consumption and indulgent consumption.

On the basis of the above studies, we predict that consumers are more willing to spend these windfall gains when they are random, single and immediate but unwilling to spend such gains when they are regular, cumulative and delayed. More importantly, in some cases, consumers adopt a certain m-payment method (e.g., Alipay or WeChat) consistently and realize that the m-payment rewards are always anticipated. They consider purchase-payment-rewards to be a closed loop and regard rewards as compensation for the purchase. However, in some other cases, consumers do not expect small or penny rewards before purchase. Their purchase behavior is supposed to be terminated just after payment. In this condition, the sudden appearance of unexpected rewards initiates a new mental account. Consumers will be more likely to give up or spend this windfall income on other subsequent choices. In other words, the source of the income influences how it is framed and hence how it is spent. Therefore, we propose that when the m-payment rewards are regular (e.g., payment rewards are a percentage of the total purchase amount), when consumers devote more effort (e.g., make cumulative purchases) to obtain the rewards, or when the rewards are delayed redemption (e.g., deduct a purchase amount next time), consumers intend to associate the m-payment rewards with the preceding purchase but separate these rewards from subsequent choices. Consequently, their intentions to donate, participate in a lottery, engage in hedonic consumption or engage in indulgent consumption decrease. We further propose that when the m-payment rewards are random, when consumers achieve the rewards once after a single purchase, or when the rewards are immediately redeemable, consumers regard those rewards as windfall gains and hence their intentions to donate, participate in a lottery, engage in hedonic consumption or engage in indulgent consumption increase. Figure 1 shows the theoretical framework of the present study. 


\section{FIGURE 1 \\ THEORETICAL FRAMEWORK}

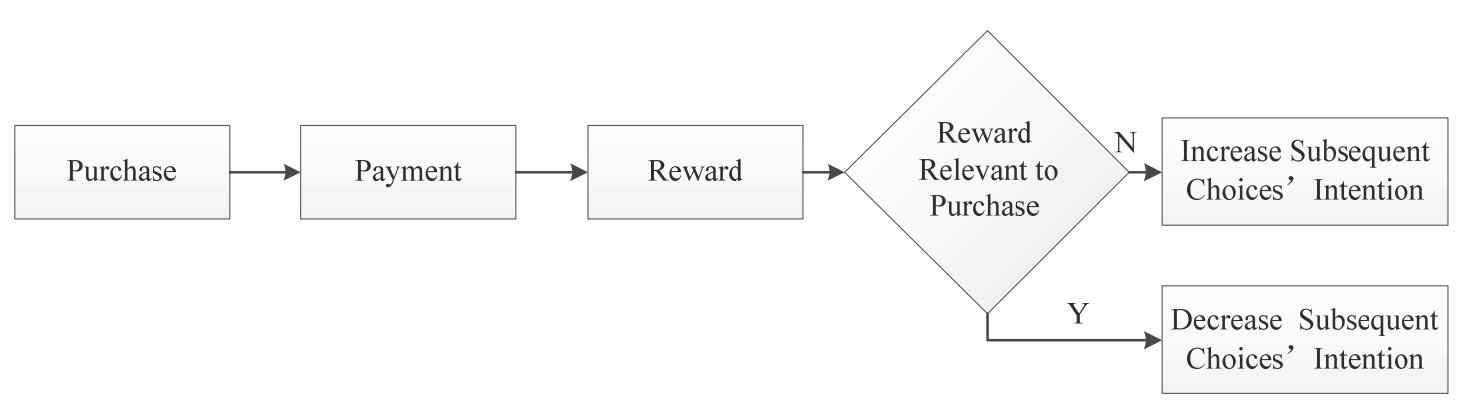

\section{THEORETICAL FOUNDATIONS AND HYPOTHESES}

Mental accounting refers to the process through which consumers categorize and frame psychological accounts of gains and losses (Thaler, 1980, 1985, 1999). Previous researches have divided mental accounts into regular income accounts and windfall gains accounts based on the source of money (Kivetz, 1999). The windfall effect, as a form of mental account framing, is defined as the high likelihood of spending extra money received aside from regular income (Bodkin, 1959). People treat windfall gains differently from regular income (Arkes et al., 1994; O'Curry and Strahilevitz, 2001; Thaler, 1985). Consumers are more likely to spend income from less important sources on frivolous expenses; conversely, they spend income from more important sources on serious expenses (Heath and O'Curry, 1994). In conclusion, consumers intend to maintain congruency between their purchase decisions and mental accounting, according to different economic incomes.

Consumers often use mental accounts to create a budget, allocate resources and make purchase decisions before incurring a new expense (e.g., Heath and Soll, 1996; Kahneman and Tversky, 1984; Soman and Cheema, 2011). However, existing studies provide little information about the relationship between mental accounting and charitable donation. Recent research has revealed that people have mental budgets for philanthropy (LaBarge and Stinson, 2014; Stinson and Howard, 2010). Past research has demonstrated how donation framing affects consumers' perceptions (Bolton and Mattila, 2015; KoschateFischer et al., 2012). Sussman et al. (2015) have investigated whether framing donations as exceptional rather than ordinary expenses might affect budgeting and donations to charity. To stimulate repeat usage, retailers often reward consumers' purchases randomly. Random payment rewards are similar to windfall gains. They are much easier to obtain than earned money. Unlike windfall or random rewards in $\mathrm{m}$ payment, some rewards are relatively regular and usually have proportional relationships with payment amounts. For example, when we pay $\$ 18$, we may receive a $\$ 0.36$ reward, which is two percent of $\$ 18$. Generally, if consumers become used to constantly adopting one payment method (e.g., Alipay or WeChat), they find that each time they pay, they obtain a reward. The regular rewards become predictable and highly relevant to the purchase compared with random rewards. People spend unexpectedly received money much more easily than they spend anticipated money (Arkes et al., 1994). Formally, we propose the following:

H1: When consumers obtain random m-payment rewards rather than regular m-payment rewards, their donation intention is higher.

According to the windfall effect, consumers can donate random m-payment rewards without restraining their original budget or accounts (Milkman and Beshears, 2009). However, when m-payment rewards are accumulated and redeemed after multiple purchases, consumers must devote continuous allocated time and effort to acquire the rewards. Achievement attribution theory (Weiner, 1985) has revealed that there are two main personal intrinsic causes for an individual's attainment: ability and effort. 
The former refers to the ability of an individual's resource allocation. The latter refers to the effort exerted to achieve a goal. The more resources allocated and effort invested, the more important the goal is (Naylor and Ilgen, 1984). Hence, consumers perceive cumulative rewards as highly relevant to their purchase and treat those rewards as deserved. Once the rewards are redeemed, the loop of purchasepayment-rewards is closed. Due to a lack of sufficient resources to launch a new account for a philanthropic budget, consumers' donation intention decreases. By contrast, the likelihood of donating increases when the m-payment rewards are provided after a single purchase because consumers regard them as windfall income and irrelevant to the purchase. Existing research on donation framing suggests that "pennies-a-day" framing can increase consumers' donation intention by disrupting the budget process (Gourville, 1998). In particular, consumers are more likely to donate $\$ 1$ per day than $\$ 365$ per year when the same amount is presented on a yearly basis (Bagchi and Li, 2010; Sussman et al., 2015). These studies support our hypothesis regarding the influence of framing types (e.g., cumulative rewards or single rewards) on charitable donation willingness. Formally, the following hypothesis is proposed:

H2: When consumers obtain rewards derived from a single purchase rather than from cumulative purchases, their donation intention is higher.

Whether to use immediate or delayed rewards is important in sales promotion (Blattberg and Neslin, 1990). Dowling and Uncle (1997) divide rewards into two types according to redemption time: immediate rewards and delayed rewards. Immediate rewards are experienced at the point of transaction (e.g., discounts), and delayed rewards are obtained or redeemed at a point after the transaction (Keh and Lee, 2006; McClure et al., 2004). The former is more effective in attracting customers, while the latter retains consumers by rewarding their future purchases (Zhang et al., 2000). According to construal level theory (Trope and Liberman, 2003, 2010), temporal distance (e.g., immediate or future) affects an individual's willingness to donate (Ein-Gar and Levontin, 2013; Liberman and Trope, 1998). Soman (1998) demonstrates that initial rewards are more attractive than future financial rewards because consumers may forget to exert an effort to redeem future rewards. The m-payment rewards can either immediately deduct the current purchase or delay a discount for the next purchase. When individuals obtain delayed rewards, the loop of purchase-payment-rewards will not be closed until the final redemption. These rewards still belong to the extant account. If consumers confront a donation appeal at this time, they are reluctant to launch a new account to donate due to limited psychological resources and budgets. By contrast, immediate rewards framed as windfall money will increase consumers' donation willingness. Formally, we present the following hypothesis:

H3: When consumers receive immediate rewards rather than delayed rewards, their donation intention is higher.

\section{STUDIES OVERVIEW}

We present four studies to test our theoretical framework and hypotheses. Study 1 examines the effect of random m-payment rewards and regular m-payment rewards on donation intention and shows that random m-payment rewards increase consumers' likelihood to donate (H1). Study 2 investigates another differential effect of a single m-payment reward and cumulative m-payment rewards on consumers' propensity to donate and demonstrates that consumers are more likely to donate when they receive a single reward than when they receive cumulative rewards (H2). Study 3 tests how immediate m-payment rewards and delayed m-payment rewards influence consumers' intention to donate and postulates that consumers who have received immediate rewards report a higher likelihood of donating than those who have received delayed rewards (H3). Finally, in study 4, we reinforce the explanation of "rewards as windfall gains" in a field experiment and test consumers' other subsequent choices including lotteries, hedonic consumption and indulgent consumption. 


\section{STUDY 1}

Study 1 was conducted to test how random m-payment rewards and regular m-payment rewards influenced donation intention. We predicted that consumers' donation intention was higher when they obtained random m-payment rewards rather than regular m-payment rewards. Because random rewards had a weak relationship with purchases, consumers framed such rewards as extra money. By contrast, regular rewards were highly relevant to purchases, and consumers framed such rewards as "serious" money.

\section{Method}

Participants and Design

One hundred thirty-three students (average age $=23.1$ years, $67.5 \%$ male) from a top university in China participated in this study, and each was paid a small bonus. This study employed a three-cell (regular rewards vs. random rewards vs. control) between-subjects design. Participants were randomly assigned to one condition.

\section{Procedure}

Those in the regular rewards condition were told that they purchased some daily necessities at one supermarket and then paid through Alipay or WeChat. After payment, they obtained one fixed reward amount (¥0.36), which was proportional to the purchase amount. Conversely, those in the random rewards condition were told they received one random reward amount (¥0.36). Those in the control condition did not obtain any rewards. Next, the payment page then presented a pop-up donation appeal: "Ten cents will help at least ten rural children drink clean water." The following is the description of this real case for Alipay:

Water purification project: help more than 40 million poor rural children drink clean water. This project is initiated by One Foundation, which was founded by Jet Li. This project was launched in 2012 and installed 1069 water purification units in 956 rural schools in 26 provinces by the end of 2017. We will continue this activity this year. We are looking forward your participation in improving the rural children's drinking situation. You can donate ten cents to help at least ten rural children drink clean water. Every child's healthy growth is inseparable from everyday safe and clean water.

There was a one-click-donation button at the bottom of the appeal. Participants could click it and donate ten cents directly. The design and layout of the appeals were identical in the three rewards conditions. Participants were then asked to respond to two questions measuring their donation intention on scales ranging from 1 (not at all) to 7 (very much): "To what extent would you like to click the "oneclick-donation' button?" and "To what extent would you like to make this ten-cent donation?" Finally, participants were paid and dismissed.

\section{Results}

First, in light of the high correlation between the two dependent measures $(\alpha=0.883)$, we collapsed them into a composite measure we called donation intention. As expected, an ANOVA showed that participants in the random rewards condition reported a higher donation intention than did those in the regular rewards and control conditions $(M=6.09$ vs. $M=5.40$ vs. $M=5.22 ; F(2,130)=5.157 ; P<$ $0.01)$. The results were consistent with $\mathrm{H} 1$.

\section{Discussion}

Study 1 suggested that compared with regular m-payment rewards, random m-payment rewards increased consumers' donation intention. Individuals who received random m-payment rewards presented a higher donation intention than did those who received regular m-payment rewards. Those in the control 
condition reported the lowest likelihood of donation. These findings supported our theoretical framework, which reflected how consumers framed the rewards. Regular rewards were framed as relevant to purchases and decreased consumers' donation intention. By contrast, random rewards were framed as windfall gains that were irrelevant to purchases and increased their donation intention. Building on these findings, study 2 continued to test the influence of rewards derived from cumulative purchases or single purchases on donation intention.

\section{STUDY 2}

The objective of our second study was to investigate the differential impact of a single reward versus cumulative rewards on donation likelihood. Specifically, we expected those who received a single mpayment reward to express greater intention to donate to charity than those who received cumulative $\mathrm{m}$ payment rewards were.

\section{Method}

Participants and Design

A total of fifty-two students (average age $=22.85,59.6 \%$ male) from a top university in China participated in this study, and each was paid a small bonus. This study employed a two-cell (single reward vs. cumulative rewards) between-subjects design. Participants were randomly assigned to one condition.

\section{Procedure}

Those in the cumulative rewards condition were asked to read the following scenario:

"Imaging that you have recently made some occasional purchases in one supermarket, and you always use Alipay or WeChat to pay. When you finish the first payment, the payment page reminds you that if you consistently use this payment channel five times in the future, you will receive a random reward at the point of the fifth purchase. In the next two weeks, you use the same payment method to make another four purchases. Finally, you get a random reward (¥0.36). ”

By contrast, those in the single reward condition were told that they received a random reward (¥0.36) after just the first purchase. They did not need to exert time and effort to reach the final goal. Next, a donation appeal that was identical to the first study appeared: "Ten cents help at least ten rural children to drink clean water." Participants then indicated the likelihood of donation on a seven-point scale $(1=$ not at all and $7=$ very much). Finally, participants were paid and dismissed.

\section{Results}

We ran an ANOVA with donation intention as the dependent variable and the framed rewards as the independent variable. The results indicated a significant main effect of the two types rewards $(F(1,50)=$ 7.249, $P=0.01)$. As predicted, participants who received a single reward expressed greater donation intention $(M=6.10, S D=1.029)$ than did those who received cumulative rewards $(M=5.14, S D=$ 1.552). These findings were consistent with $\mathrm{H} 2$.

\section{Discussion}

Study 2 found that consumers who obtained single rewards were more likely to donate to a charity than those who obtained cumulative rewards. On the basis of the results in the first study, we used only random rewards stimuli. Random rewards promote donation intention. Most importantly, cumulative random rewards decreased an individual's donation likelihood because consumers perceived cumulative rewards as hard-earned money and highly relevant to their purchase. They exerted time and effort to redeem the final reward. Based on their limited resources, consumers showed unwillingness to launch a new account to donate. These findings provided robust evidence for our theoretical framework. 


\section{STUDY 3}

Study 3 aimed to test another differential effect of immediate m-payment rewards versus delayed mpayment rewards on charitable giving intention. In particular, we predicted that those who received immediate m-payment rewards reported a higher donation intention to a charity than did those who received delayed m-payment rewards.

\section{Method}

Participants and Design

A total of eighty-two students (average age $=23.54,54.9 \%$ male) from a top university in China participated in this study, and each was paid a small bonus. We employed a two-cell (immediate rewards vs. delayed rewards) between-subjects design. Participants were randomly assigned to one condition.

\section{Procedure}

Those participants in the immediate rewards condition read the following scenario first:

"Imagine that you purchase some daily necessities in one supermarket. The total cost is $¥ 18$. You use mobile payment (Alipay or WeChat) to pay. When you conduct the payment, you surprisingly find that you receive a reward of $¥ 0.36$. This reward is deducted from your cost immediately, and you ultimately pay $¥ 17.64$.”

By contrast, participants in the delayed rewards condition read the same scenario, with the exception of the restraint on the use of the rewards: "The rewards have been deposited in your wallet account. There are no valid restrictions on its use. As long as you pay again, it will offset the purchase amount." Next, the same donation appeal from the first study appeared, and participants indicated their donation intention in response to this appeal on a seven-point scale $(1=$ not at all and $7=$ very much). Finally, participants were paid and dismissed.

\section{Results}

We first collapsed the two dependent variables into a composite measure also called donate intention $(\alpha=0.854)$. We then conducted an ANOVA with donation intention as the dependent variable and the framed rewards as the independent variable. As expected, the results indicated a significant main effect of the two reward types $(F(1,80)=9.255, P<0.01)$. In particular, participants who received immediate rewards expressed greater donation intention $(M=6.31, S D=0.855)$ than did those who received cumulative rewards $(M=5.52, S D=1.389)$. These findings were consistent with $\mathrm{H} 3$.

\section{Discussion}

In this study, we manipulated participants' received rewards to examine how immediate rewards and delayed rewards influenced individuals' donation intention. Our findings revealed that participants who received immediate rewards showed a greater donation likelihood to a charity than did those who received delayed rewards. Individuals framed immediate rewards as random windfall income. The immediate rewards fell into a new account that encouraged them to donate because the extant loop of purchase-payment-rewards had been closed, whereas the delayed rewards remained in the loop, and individuals showed an unwillingness to donate due to limited psychological resources. These findings further support the robustness of our theoretical framework.

\section{STUDY 4}

The objectives of study 4 were twofold. First, we aimed to reinforce the explanation of "rewards as the windfall gains." More directly, we tested how consumers coded and categorized m-payment rewards in a field experiment. In study 4a, we investigated how consumers made trade-offs between two options 
in a real context. One choice had a more rational appeal (Hsee et al., 2014), collecting m-payment rewards, and the other choice had a more attractive appeal, participate in a lottery. The framing effect indicated that individuals were risk averse for decisions framed as gains but risk seeking for decisions framed as losses (Tversky and Kahneman, 1981). If consumers framed the m-payment rewards as deserved and highly relevant to their purchase, they should favor choosing these rewards, whereas if consumers framed the m-payment rewards as extra or windfall gains, they ought to favor choosing the lottery. Second, we expanded alternative subsequent choices or preferences except for donation. Windfall income was mostly spent on hedonic consumption (Shafir and Thaler, 2006; Thaler, 1985; Thaler and Shefrin, 1981), as it was more frivolous. By contrast, regular income, such as salary, were seen as serious and less likely to be spent on luxury items (Thaler and Shefrin, 1981). In study 4b, we investigated the effect of the m-payment awards on hedonic consumption and indulgent consumption and tested the robustness of our theoretical framework from alternative perspectives.

\section{Study 4a}

The purpose of this study was to conduct a field experiment to test consumers' trade-offs between two options: collect the m-payment rewards and give up the lottery or give up the m-payment rewards to participate in the lottery. We predicted that when consumers framed a single m-payment reward as irrelevant to their purchase, they intended to choose the lottery and give up the rewards, whereas when consumers framed cumulative m-payment rewards as relevant to their purchase, they were risk averse and collected the rewards.

\section{Method}

Participants and Design. A total of forty-four students (average age $=20.07,52.3 \%$ male) from a top university in China participated in this study. This study employed a two-cell (single reward vs. cumulative rewards) between-subjects design. Participants were randomly assigned to one condition.

Procedure. The priming scenarios of a single reward and cumulative rewards were the same as in study 2. However, we turned the imagined rewards into real rewards. After the participants read the scenarios, they scanned a unique and real QR code with their smartphones to receive rewards that actually went straight into their own account. Next, the dependent variables were the trade-off choice between the rewards and the lottery. Participants responded to two questions: "To what extent would you choose the lottery?" and "What is the degree of your preference for the lottery" on seven-point scales $(1=$ not at all and $7=$ very much).

\section{Results}

We first collapsed the two dependent variables into a composite measure called intention to participate in the lottery $(\alpha=0.895)$. We then conducted an ANOVA with the trade-off choice as the dependent variable and the framed rewards as the independent variable. As our proposed rationale, the results indicated a significant main effect of the two type rewards $(F(1,42)=7.624, P<0.01)$. Participants who received a single reward reported a higher intention to choose the lottery than did those who received cumulative rewards $(M=5.17, S D=1.26$ vs. $M=3.98, S D=1.55)$. These results supported our prediction.

\section{Study 4b}

The purpose of this study was to investigate consumers' alternative consumptions after obtaining mpayment rewards. The first alternative was hedonic consumption, and the second was indulgent consumption. We predicted that compared to cumulative rewards, a single reward would increase consumers' propensity for hedonic and indulgent items.

\section{Method}

Participants and Design. One hundred twenty-three students (average age $=21.5,32.5 \%$ male) and forty-six students (average age $=21.52,47.8 \%$ male) from a top university in China participated in the 
hedonic consumption condition and the indulgent consumption condition, respectively. In each condition, we employed a two-cell (hedonic vs. utilitarian and more indulgent vs. less indulgent) between-subjects design. Every participant was paid a small bonus.

Procedure. The priming scenarios of a single reward and cumulative rewards were the same as in study 2 except for the reward amounts. In study 2, the m-payment rewards were $¥ 0.36$, and the donation appeal was ten cents. The rewards covered the donation amount. However, in the hedonic consumption condition, we exaggerated the rewards amount proportionately (¥10.80), which was slightly less than the consumption amount (¥12.0). In the indulgent consumption condition, we manipulated the m-payment rewards $(¥ 3.60)$ to be identical to the consumption amount (¥3.60). Next, participants in the hedonic consumption condition read the following scenario, which was modified on the basis of Helion and Gilovich (2014):

After you collect the m-payment rewards, the payment page recommends two purchasing links based on your browsing history. One of them is a novel written by your favorite author. The other one is a reference book for one of your courses. The prices are all $¥ 12.0$.

Then, participants were also asked to indicate their preferences toward the two choices: in which book were they more interested $(1=$ very interested in reference book, $7=$ very interested in novel $)$, which link would they click first $(1=$ very likely to click the link to the reference book, $7=$ very likely to click the link to the novel) and which book was more in line with their purchase intention if they were considering buying one ( 1 = very likely to buy the reference book, 7 = very likely to buy the novel $)$. We also asked participants several other questions, such as "To what extent do you think the reference book or the novel was utilitarian?" $(1=$ the reference book was very utilitarian, $7=$ the novel was very utilitarian) and "To what extent do you think the reference book or the novel was hedonic?" $(1=$ the reference book was very hedonic, $7=$ the novel was very hedonic).

In the indulgent consumption condition, participants read the scenario as follows:

After you collect the m-payment rewards, you notice two potato chips are being promoted. A is your favorite chips, but they are fried, high in calories and unhealthy. $B$ is not your favorite chips, but they are not fried, low in calories and healthy. The prices are all $¥ 3.60$.

Then, participants were asked to report their preferences toward the two types of chips: which chips were more attractive to them $(1=\mathrm{B}$ chips were very attractive, $7=\mathrm{A}$ chips were very attractive $)$, and which chips were more in line with their purchase intention if they were considering buying one $(1=$ very likely to buy B chips, 7 = very likely to buy A chips). Participants also answered another question, "Which consumption do you think was indulgent?" $(1=$ purchase B chips were very indulgent, $7=$ purchase A chips were very indulgent). Finally, the participants were paid and dismissed.

\section{Results}

Hedonic consumption. An ANOVA with purchase intention of the books as the dependent measure and the single reward or cumulative rewards as the independent measures elicited only a main effect of rewards types $(F(1,121)=5.656, P<0.05)$, indicating that participants who received a single reward were more likely to buy the novel than the reference book than were those who received cumulative rewards $(M=4.03, S D=1.597$ vs. $M=3.28, S D=1.875)$. Participants also treated the novel as more hedonic $(M=5.46$ vs. $M=4.00, S D=1.326, P<0.001)$ than the reference book was.

Indulgent consumption. An ANOVA with the purchase intention of potato chips as the dependent measure and the single reward or cumulative rewards as the independent measures elicited only a main effect of rewards types $(F(1,44)=15.473, P<0.001)$, indicating that compared to those who received cumulative rewards, participants who received a single reward were more likely to buy the more attractive 
chips than less attractive chips $(M=5.83, S D=1.136$ vs. $M=4.29, S D=1.490)$. Participants also regarded purchasing the more attractive chips as more indulgent $(M=5.26 \mathrm{vs} . M=4.00, S D=1.341, P<$ $0.001)$.

\section{Discussion}

First, regardless of whether the hedonic consumption condition or the indulgent consumption condition is used, we used only a single reward and cumulative rewards as stimuli rather than using the other rewards types (e.g., random vs. regular and immediate vs. delayed) because the former types were more representative and more common in a real purchase context than the latter types were. Hence, we chose the former types as our independent variables. Second, when participants obtained a single reward, they expressed a higher preference for the hedonic novel than they did for the utilitarian reference book. Although the main effect had been proved, the preference trend had been attenuated by student samples. Third, the reward amount (whether it would cover the purchase) did not influence consumers' donation intention or consumption behavior.

\section{GENERAL DISCUSSION}

M-payment is becoming increasingly prevalent in our daily lives. It has drastically changed consumers' purchase mode (Slade et al., 2015). It is secure, fast and convenience. Almost all payment applications provide rewards to encourage consumers' repeat usage. Consumers regard regular, cumulative and delayed rewards as compensation for their consumption and closely connect such rewards to their purchase and thus classifying such rewards into serious income accounts and spending them sparingly. By contrast, consumers classify random, single and immediate rewards into windfall accounts that are irrelevant to their purchase and easily spent. However, how do consumers dispose of these windfall rewards? The current paper demonstrates that small rewards leverage big changes for people who are need. Those payment rewards promote donation intention. Three studies provide robust evidence for the relationship between m-payment rewards types and donation intention. Study 1 reveals that random m-payment rewards increase consumers' intention to donate to a charity, whereas regular rewards are expected and predictable, and they decrease consumers' intention to donate. Study 2 investigates another differential influence of a single reward versus cumulative rewards on donation likelihood. Consumers must exert time and effort to obtain cumulative rewards. From a psychological perspective, consumers' ownership of such cumulative rewards is strong. It is similar to hard-earned money and hard to spend. However, a single reward is irrelevant to the consumer's purchase, and it increases consumers' donation intention. Study 3 further explores the effect of immediate rewards and delayed rewards on donation intention. Consumers also frame immediate rewards as extra money, which increases their donation intention. Delayed rewards remain in the purchase-payment-rewards loop and are highly relevant to the purchase, thus decreasing consumers' donation intention. In conclusion, how consumers frame payment rewards play a determinant role in the account classification and consumers' subsequent behavioral choices. More importantly, we expand our theoretical framework from alternative perspectives: hedonic consumption and indulgent consumption. Studies $4 \mathrm{a}$ and $4 \mathrm{~b}$ demonstrate that a single reward increases consumers' propensity to participate in a lottery, purchase hedonic or indulgent items. The framing of m-payment rewards affects all other subsequent choices or preferences except for donation. These findings test our theoretical framework more directly.

\section{THEORETICAL CONTRIBUTIONS}

Theoretically speaking, we focus on a prevalent payment phenomenon that is totally different from other payment means (e.g., cash and credit card). Few empirical studies test the influence of m-payment rewards on consumer behavior. The current study adds to the literature in several ways. First, we contribute to the m-payment literature from a consumer behavior perspective. The results enrich the abundant studies on payment methods that focus on cash and credit cards (Chen et al., 2017; Raghubir 
and Srivastava, 2008; Soman, 2001, 2003) but not on m-payments. Second, we explore the differential rewards effect on consumers' subsequent choices or preferences. Most importantly, we advance a totally new framework in which the way consumers frame rewards impact their subsequent behaviors. If they frame the rewards as relevant to their purchase, their subsequent behavior intentions decrease or vice versa. Third, we also enrich mental accounting theories from the donation perspective and identify a relationship between psychological accounts and donation behavior (e.g., Koschate-Fischer et al., 2012; Sussman et al., 2015).

\section{MANAGERIAL IMPLICATIONS}

From a managerial perspective, these results offer implications for companies that provide mpayment rewards. These companies can maximize the utility of the rewards in different ways. First, small or penny m-payment rewards will make the donation of small amounts easily successful. Even though the donation amounts are small, a one-penny donation will leverage big changes through its cumulative effect. Whether the donation is on behalf of the consumers or the companies, m-payment rewards have a positive effect on society. Second, m-payment rewards can be spent on hedonic and indulgent consumptions as compensation for purchase. If companies want to promote consumers' constant usage and frequent purchases as much as possible, they should design the m-payment rewards elaborately and ensure that consumers are more likely to spend the rewards. Third, companies can recommend target objects to consumers by analyzing their browsing histories. Precise marketing will be more effective and will increase the likelihood of purchasing to the greatest extent.

\section{LIMITATIONS AND FUTURE DIRECTIONS}

The limitations of the present study reveal several opportunities for future research. First, we should investigate some psychological mechanisms. Pain of payment, happiness or psychological possession may provide a mediating effect. Second, we should test other consumer behaviors to reinforce the relationship between m-payment rewards and subsequent behaviors and explore alternative utilities of payment rewards. The current research adds a piece to this research topic, which we are only beginning to explore.

\section{ACKNOWLEDGEMENT}

The authors are very grateful to be supported by the National Natural Science Foundation of China (71772104).

\section{REFERENCES}

Arkes, H. R., Joyner, C. A., Pezzo, M. V., Nash, J. G., Siegel-Jacobs, K., \& Stone, E. (1994). The psychology of windfall gains. Organizational Behavior and Human Decision Processes, 59(3), 331-347.

Bagchi, R., \& Li, X. (2010). Illusionary progress in loyalty programs: magnitudes, reward distances, and step-size ambiguity. Journal of Consumer Research, 37(5), 888-901.

Bhattacharya, U., Holden, C. W., \& Jacobsen, S. (2012). Penny wise, dollar foolish: Buy-sell imbalances on and around round numbers. Management Science, 58(2), 413-431.

Blattberg, R. C., \& Neslin, S. A. (1990). Sales promotion: Concepts, methods, and strategies. Prentice Hall.

Bodkin, R. (1959). Windfall income and consumption. The American Economic Review, 49(4), 602-614.

Bolton, L. E., \& Mattila, A. S. (2015). How does corporate social responsibility affect consumer response to service failure in buyer-seller relationships? Journal of Retailing, 91(1), 140-153. 
Chen, R., Xu, X., \& Shen, H. (2017). Go beyond just paying: Effects of payment method on level of construal. Journal of Consumer Psychology, 27(2), 207-217.

De Kerviler, G., Demoulin, N. T., \& Zidda, P. (2016). Adoption of in-store mobile payment: Are perceived risk and convenience the only drivers? Journal of Retailing and Consumer Services, 31, 334-344.

Dowling, G. R., \& Uncles, M. (1997). Do customer loyalty programs really work? Sloan Management Review, 38(4), 71-82.

Ein-Gar, D., \& Levontin, L. (2013). Giving from a distance: Putting the charitable organization at the center of the donation appeal. Journal of Consumer Psychology, 23(2), 197-211.

Gilpatric, S. M. (2009). Slippage in rebate programs and present-biased preferences. Marketing Science, 28(2), 229-238.

Gourville, J. T. (1998). Pennies-a-day: The effect of temporal reframing on transaction evaluation. Journal of Consumer Research, 24(4), 395-408.

Gourville, J. T., \& Soman, D. (2011). The consumer psychology of mail-in rebates. Journal of Product \& Brand Management, 20(2), 147-157.

Heath, C., \& O'curry, S. (1994). Mental accounting and consumer spending. Advances in Consumer Research, (21), 119.

Heath, C., \& Soll, J. B. (1996). Mental budgeting and consumer decisions. Journal of Consumer Research, 23(1), 40-52.

Helion, C., \& Gilovich, T. (2014). Gift cards and mental accounting: Green-lighting hedonic spending. Journal of Behavioral Decision Making, 27(4), 386-393.

Hsee, C. K., Yang, Y., Zheng, X., \& Wang, H. (2015). Lay rationalism: Individual differences in using reason versus feelings to guide decisions. Journal of Marketing Research, 52(1), 134-146.

Janiszewski, C., \& Uy, D. (2008). Precision of the anchor influences the amount of adjustment. Psychological Science, 19(2), 121-127.

Kahneman, D., \& Tversky, A. (1984). Choices, values, and frames. American Psychologist, 39(4), 341 350.

Keh, H. T., \& Lee, Y. H. (2006). Do reward programs build loyalty for services? The moderating effect of satisfaction on type and timing of rewards. Journal of Retailing, 82(2), 127-136.

Kivetz, R. (1999). Advances in research on mental accounting and reason-based choice. Marketing Letters, 10(3), 249-266.

Koschate-Fischer, N., Stefan, I. V., \& Hoyer, W. D. (2012). Willingness to pay for cause-related marketing: The impact of donation amount and moderating effects. Journal of Marketing Research, 49(6), 910-927.

LaBarge, M. C., \& Stinson, J. L. (2014). The role of mental budgeting in philanthropic decision-making. Nonprofit and Voluntary Sector Quarterly, 43(6), 993-1013.

Liberman, N., \& Trope, Y. (1998). The role of feasibility and desirability considerations in near and distant future decisions: A test of temporal construal theory. Journal of Personality and Social Psychology, 75(1), 5-18.

Lu, Q., \& Moorthy, S. (2007). Coupons versus rebates. Marketing Science, 26(1), 67-82.

Mallat, N. (2007). Exploring consumer adoption of mobile payments-A qualitative study. The Journal of Strategic Information Systems, 16(4), 413-432.

McClure, S. M., Laibson, D. I., Loewenstein, G., \& Cohen, J. D. (2004). Separate neural systems value immediate and delayed monetary rewards. Science, 306(5695), 503-507.

Milkman, K. L., \& Beshears, J. (2009). Mental accounting and small windfalls: Evidence from an online grocer. Journal of Economic Behavior \& Organization, 71(2), 384-394.

Mobile Payment Transaction Volume 2010-2017. (2015). Mobile payment transaction volume 20102017. Retrieved from www.statista.com/statistics/.

Naylor, J. C., \& Ilgen, D. R. (1984). Goal setting: A theoretical analysis of a motivational technology. Research in Organizational Behavior, 6(1), 95-140. 
O'curry, S., \& Strahilevitz, M. (2001). Probability and mode of acquisition effects on choices between hedonic and utilitarian options. Marketing Letters, 12(1), 37-49.

Raghubir, P., \& Srivastava, J. (2008). Monopoly money: The effect of payment coupling and form on spending behavior. Journal of Experimental Psychology: Applied, 14(3), 213-225.

Schindler, R., \& Yalch, R. (2006). It seems factual, but is it? Effects of using sharp versus round numbers in advertising claims. Advances in Consumer Research, 33, 586.

Shafir, E., \& Thaler, R. H. (2006). Invest now, drink later, spend never: On the mental accounting of delayed consumption. Journal of Economic Psychology, 27(5), 694-712.

Shah, A. M., Eisenkraft, N., Bettman, J. R., \& Chartrand, T. L. (2015). "Paper or plastic?”: How we pay influences post-transaction connection. Journal of Consumer Research, 42(5), 688-708.

Slade, E., Williams, M., Dwivedi, Y., \& Piercy, N. (2015). Exploring consumer adoption of proximity mobile payments. Journal of Strategic Marketing, 23(3), 209-223.

Soman, D. (1998). The illusion of delayed incentives: Evaluating future effort-money transactions. Journal of Marketing Research, 35(4), 427-437.

Soman, D. (2001). Effects of payment mechanism on spending behavior: The role of rehearsal and immediacy of payments. Journal of Consumer Research, 27(4), 460-474.

Soman, D. (2003). The effect of payment transparency on consumption: Quasi-experiments from the field. Marketing Letters, 14(3), 173-183.

Soman, D., \& Cheema, A. (2011). Earmarking and partitioning: increasing saving by low-income households. Journal of Marketing Research, 48(SPL), S14-S22.

Stinson, J. L., \& Howard, D. R. (2010). Intercollegiate athletics as an institutional fundraising tool: An exploratory donor-based view. Journal of Nonprofit and Public-Sector Marketing, 22(4), 312335.

Sussman, A. B., Sharma, E., \& Alter, A. L. (2015). Framing charitable donations as exceptional expenses increases giving. Journal of Experimental Psychology: Applied, 21(2), 130-139.

Thaler, R. (1980). Toward a positive theory of consumer choice. Journal of Economic Behavior and Organization, 1(1), 39-60.

Thaler, R. (1985). Mental accounting and consumer choice. Marketing Science, 4(3), 199-214.

Thaler, R. H. (1999). Mental accounting matters. Journal of Behavioral Decision Making, 12(3), 183-206.

Thaler, R. H., \& Shefrin, H. M. (1981). An economic theory of self-control. Journal of Political Economy, 89(2), 392-406.

Thomas, M., \& Morwitz, V. (2005). Penny wise and pound foolish: The left-digit effect in price cognition. Journal of Consumer Research, 32(1), 54-64.

Thomas, M., Simon, D. H., \& Kadiyali, V. (2010). The price precision effect: Evidence from laboratory and market data. Marketing Science, 29(1), 175-190.

Trope, Y., \& Liberman, N. (2003). Temporal construal. Psychological Review, 110(3), 403-421.

Trope, Y., \& Liberman, N. (2010). Construal-level theory of psychological distance. Psychological Review, 117(2), 440-463.

Tversky, A., \& Kahneman, D. (1981). The framing of decisions and the psychology of choice. Science, 211(4481), 453-458.

Weiner, B. (1985). An attributional theory of achievement motivation and emotion. Psychological Review, 92(4), 548-573.

Wieseke, J., Kolberg, A., \& Schons, L. M. (2016). Life could be so easy: The convenience effect of round price endings. Journal of the Academy of Marketing Science, 44(4), 474-494.

Zhang, Z. J., Krishna, A., \& Dhar, S. K. (2000). The optimal choice of promotional vehicles: Frontloaded or rear-loaded incentives? Management Science, 46(3), 348-362. 